\title{
Bourdieu e foucault: derivas de um espaço epistêmico
}

José Carlos do Anjos*

Resumo. Neste artigo, o autor discute as bases epistemológicas bachelardianas das obras de Bourdieu e Foucault tendo em vista avaliar-lhes a pertinência para uma sociologia da Modernidade na periferia. O que Bachelard fundou foi uma modalidade de reconstrução racional associada a uma historização que se contrapõe ao positivismo na medida em que enfatiza o caráter criativo e inventivo da fenomenotécnica científica. Bourdieu assume de Bachelard a injunção à ruptura epistemológica entre o fenômeno que se reconstitui na ciência e aquele que se apresenta ao senso comum. Foucault usa o modo de demonstração bachelardiano das raízes fantásticas das ciências para desmantelar as pretensões das ciências humanas. Sugere-se, neste artigo, que a extensão da posição epistemológica foucaultiana é heuristicamente mais fecunda e permanece promissora para os lugares de enunciação com pretensão de desvelamento do modo como a Modernidade apresenta-se na periferia.

Palavras-chave: Michel Foucault. Pierre Bourdieu. Gaston Bachelard. Modernidade.

\section{Introdução}

Quando parece ter soado a hora do balanço na produção de toda uma geração de intelectuais franceses que marcaram a segunda metade do século $\mathrm{XX}$, poucas das séries de avaliações que o falecimento de Pierre Bourdieu desencadeou e que a comemoração

* José Carlos dos Anjos é professor do Departamento de Sociologia e do PPG em Sociologia da UFRGS.

Anos 90, Porto Alegre, v. 11, n. 19/20, p.139-165, jan./dez. 2004 
do vigésimo ano de falecimento de Michel Foucault reabriu voltaram-se para os fundamentos epistemológicos de todo esse movimento intelectual para avaliar-lhe as possibilidades de continuidades e os perfis de superações no acúmulo. $\mathrm{Na}$ verdade, tais balancetes parciais vêm sendo feitos, desde a década de setenta, a cada falecimento, de Barthes a Deleuze, passando por Poulantzas, Lacan, Althusser, sem que se aponte, nos espólios desses que os detratores rapidamente cunharam de "estruturalistas" ou "pósestruturalistas", como as superações desenham-se nas brechas dos acúmulos possíveis. Sobretudo pouco se avaliou sobre o transplante desse tipo de estrutura teórica engendrada nas condições específicas dos países centrais quando utilizada em análises cujo foco empírico é a modernidade periférica.

As ênfases dominantes na busca dos nódulos centrais desse pensamento, quando não homogeneízam essa geração de pensadores sob supostas premissas comuns estruturalistas, destacam traços idiossincráticos que também impedem comparações mais sérias. Assim, se ressalta ora o veio Nietzscheano de Foucault, ora a grande síntese dos clássicos da Sociologia em Bourdieu, não se percebendo o que os dois pensadores têm em comum e que os diferencia de Althusser, Barthes e Poulantzas, por exemplo. Este artigo pretende ressaltar que o potencial universalizador das análises contidas nas obras de Foucault e Bourdieu deve-se a uma especial proposta de articulação entre as dimensões teórica e empírica das pesquisas de modo a tornar a teoria sempre uma reinvenção a cada obra. $\mathrm{O}$ texto busca ainda destacar o quanto Bachelard e Canguilhem são os obreiros menos visíveis desse subsolo epistêmico onde comumente se encontra estampada a presença ou do estruturalismo, ou de Nietzsche.

\section{História das ciências deslocando o tribunal da razão}

É fácil demonstrar que os "estranhos anos 60" do debate filosófico e sociológico francês provêm de uma mesma matriz filosófico-epistêmica - até porque Foucault, Bourdieu e seus

Anos 90, Porto Alegre, v. 11, n. 19/20, p.139-165, jan./dez. 2004 
comentadores repetem, à exaustão, serem contra o existencialismo sartriano ao qual Bachelard e Canguilhem foram jogados de modo a abrir um novo espaço de problemas alheios "à filosofia do sentido, do sujeito e do vivido" que marcou a apropriação da fenomenologia na França dos anos 50.

Mas suprimam Canguilhem e vocês não compreenderão mais grande coisa de toda essa série de discussões que ocorreram entre os marxistas franceses; vocês não mais apreenderão o que há de especifico em sociólogos como Bourdieu, Castel, Passeron, e que os marca tão intensamente no campo da sociologia [...] (Foucault, 2000, p. 353).

E o que os marca tão intensamente?

Sugere Foucault (2000) que é a historização radical do "saber, da racionalidade e do conceito". A meu ver, essa historicização que pode ser tomada como o "a prior" do pensamento contemporâneo - dá-se na França, com três marcas distintivas: 1) a ênfase na descontinuidade dos processos de reorganização do saber, de modo a se desconstituírem, simultaneamente, as pretensões de uma história de acumulação linear de conhecimentos e a busca de fundamentações filosóficas últimas para as ciências; 2) em segundo lugar, o radicalismo da aposta no caráter construído do objeto científico, que retira quaisquer possibilidades de aproximação entre a construção sociológica ou arquegenealógica e as teorias nativas, o senso comum, a doxa instituída ou as retóricas militantes; 3) por fim, a recusa a reflexões intimistas, tanto na relação leitor e autor quanto nas possibilidades de exposição da comunhão intersubjetiva entre o pesquisador e o pensamento e emoções dos pesquisados. Essa recusa dá-se em favor de uma reflexividade que toma para análise não a intimidade dos sujeitos, mas a estrutura do mundo escolástico de onde emanam as possibilidades de enunciação em jogo. Tanto em Bourdieu como em Foucault, está em jogo analisar e expor o saber escolástico enquanto o lugar de emanação de formas de racionalização do social que institucionalizam relações de poder.

Anos 90, Porto Alegre, v. 11, n. 19/20, p.139-165, jan./dez. 2004 
Passo a explicitar a presença de Bachelard em cada um dos três pontos. Desde Bachelard, é incisiva, na França, a historização radical dos "modos do dizer verdadeiro", seus efeitos de poder, conjuntamente com a rejeição à chantagem de que a recusa às filosofias primeiras do conhecimento, em favor da historicização do saber, significaria uma queda no irracionalismo. Se o saber científico não é tomado como simplesmente progressivo, a reconstrução das possibilidades do jogo entre o verdadeiro e o falso precisa ser recolocada em novos termos. Retificar, corrigir, reconstituir continuamente os modos do "dizer o verdadeiro" significa, simultaneamente, que o jogo do esclarecimento produz clareiras e que a acumulação nunca se deixa organizar na longa narrativa do encontro do "homem" com "a verdade".

Concebendo que ela se relaciona com a história dos "discursos verídicos", ou seja, com os discursos que se retificam, se corrigem, e que operam em si mesmos todo um trabalho de elaboração finalizado pela tarefa do dizer verdadeiro (Foucault, 2000, p. 339).

O segundo tópico, a noção de objeto construído, também tem uma regularidade em larga medida fundada na epistemologia de Bachelard. É de Bachelard a noção de que a pesquisa deve reivindicar um realismo próprio da ciência, uma busca da "realidade" que não se compromete com os fenômenos na forma como se apresentam ao senso comum. ${ }^{1}$ Em Bachelard, o "real" já sempre está em relação dialética com a "razão científica", precisando ser reconstruído em laboratório. Acima do sujeito e além do objeto imediato, a ciência moderna funda-se no projeto enquanto mediação de um fenômeno que só se apresenta através da teoria encarnada nas técnicas de pesquisa. A experimentação funde o fenômeno, após depurado, nos moldes dos instrumentos científicos, e desses instrumentos devemos dizer que são teorias materializadas em formas laboratoriais. Não há fenômeno científico sem a marca da teoria, e a teoria científica demarca-se como "trabalho" porque encarna-se em instrumentos

Anos 90, Porto Alegre, v. 11, n. 19/20, p.139-165, jan./dez. 2004 
de pesquisa. Nesse sentido, a observação científica é sempre uma observação polêmica, é sempre construída numa insurgência contra o modo como o fenômeno apresenta-se ao senso comum e como se apresentou no estágio anterior ao labor científico. Nessa injunção epistêmica, não há separação entre a observação científica e a demonstração, entre a demonstração e a polêmica contra o erro. A ciência reconstrói o "real" reconstruindo teoricamente seus esquemas e instrumentos de apreensão num refazer contra o que já foi feito e visto.

Percebe-se com nitidez esse conjunto de injunções epistêmicas nos poucos extratos mais "metodológicos" dos escritos de Foucault. Tratando da evidência com que a "obra" ou o "livro" impõe suas fronteiras ao senso comum, Foucault reduplica a insurgência de Bachelard contra a nitidez dos objetos que se apresentam como "dados":

Trata-se, de fato, de arrancá-las de sua quase-evidência, de liberar os problemas que colocam; reconhecer que não são o lugar tranqüilo a partir do qual outras questões podem ser levantadas (sobre a sua estrutura, sua coerência, sua sistematicidade, suas transformações), mas que colocam por si mesmas todo um feixe de questões (que são? Como defini-las ou limitálas? A que subconjuntos podem dar lugar? Que fenômenos específicos fazem aparecer no campo do discurso?). Trata-se de reconhecer que elas talvez não sejam, afinal de contas, o que se acreditava que fossem à primeira vista. Enfim, que exigem uma teoria (Foucault, 1987, p. 29).

Reconstruir laboriosamente um objeto é destruir sua evidência para, no lugar do senso estabelecido, fazer emergir um feixe de relações de força de que a "aparência" - o objeto em sua forma primeira - é apenas uma parte, um modo de funcionamento. $\mathrm{O}$ papel da teoria na reconstrução do objeto é, fundamentalmente, o de impor rupturas: não só contra a aparência, polemizando contra a

Anos 90, Porto Alegre, v. 11, n. 19/20, p.139-165, jan./dez. 2004 
evidência com que o "real" se nos apresenta, mas também contra a busca do sentido ou da verdade do fenômeno na intenção do ator (ou autor de uma obra):

Para estarmos seguros de não relacioná-la com operadores de síntese puramente psicológicos (a intenção do autor, a forma de seu espírito, o rigor de seu pensamento, os temas que o obcecam, o profeta que atravessa sua existência e lhe dá significação) e podermos apreender outras formas de regularidade, outros tipos de relações (Foucault, 1987, p. 29).

A injunção à ruptura com o senso estabelecido (como comum, institucional ou científico) obseda de forma mais intensa ainda os escritos de Bourdieu, inserido como esteve na reconstrução dos fundamentos metodológicos dessa ciência - a Sociologia - que lhe parecia particularmente historicizante. Reconstruir o objeto científico é expor estruturas não-evidentes, historicamente contingentes e que tornam possíveis as evidências da doxa estabelecida, comum ou escolástica. É numa luta contra a doxa estabelecida que a reorganização conceitual destrói o objeto préconstruído, para fazer emergir o inusitado:

Todavia, construir um objeto cientifico é, antes mais e, sobretudo, romper com o senso comum, quer dizer, com as representações partilhadas por todos, quer se trate dos simples lugares-comuns da existência vulgar, quer se trate das representações oficiais, freqüentemente inscritas nas instituições, logo, ao mesmo tempo, na objetividade das organizações sociais e nos cérebros (Bourdieu, 1999, p. 34).

Dos três tópicos listados acima, restaria ainda destacar que, da história das ciências, tal como iniciada por Bachelard, resulta um tipo de exercício de reflexividade que tende a colocar sob suspeita a própria instituição de onde emana a pretensão crítica da razão. É,

Anos 90, Porto Alegre, v. 11, n. 19/20, p.139-165, jan./dez. 2004 
em primeiro lugar, a própria posição de crítico que se transforma num lugar incômodo, submetido a um implacável processo de objetivação. Mas a recusa a esse lugar, cunhado de "posição do intelectual total", emblematicamente atribuído à figura de Sartre, toma direções diferentes: Bourdieu e Foucault representam, no seguimento da história das ciências, de Bachelard, duas possibilidades de saída para a questão da historicidade do saber filosófico que evitam, simultaneamente, cair numa filosofia da história com seus riscos de totalização no presente como realização e exegese absoluta do passado e o perigo correlato do historicismo, que reduziria as estruturas internas dos processos de cognição às contingências dos fatores que externos a cognoscibilidade.

O primeiro risco foi enfrentado de forma mais obsessiva por Bourdieu, a ponto de lhe impor um deslocamento para fora da Filosofia e uma aposta radical na sociologia do saber escolástico; o segundo risco, o do historicismo relativista, está mais equacionado por Foucault, e é contra esse último risco que emerge a alternativa de uma ontologia da vida e do poder. Mas ambos se colocam na busca de alternativas entre Hegel e Heidegger. A questão é escapar de uma filosofia que "valida a si mesma através de sua própria soberania" e evitar ter que cair numa relativização tal da razão que esta "não pode ser dissociada, em sua história, das inércias, dos embotamentos e das coerções que a submetem" (Bourdieu, 1998, p. 357).

Sob a injunção de uma reflexão radical sobre o lugar de onde emana o discurso com pretensão de ponto-de-vista privilegiado sobre o real, Bourdieu deserta de vez de qualquer tentativa de buscar, na filosofia das ciências, bases epistemológicas para a praxiologia a que se propõe. As críticas às pretensões fundamentadoras de sua disciplina de origem levam-no a uma Sociologia reconstruída teoricamente como espaço por excelência da destituição das arrogâncias do pensamento escolástico. O que está em jogo é historizar a "pretensão ao domínio exclusivo de uma verdade", levando-se em conta que se está enunciando num espaço de uma multiplicidade de visões em combate. Todos os empreendimentos filosóficos mais relevantes para resolver a contradição - de dizer historicamente a verdade das

Anos 90, Porto Alegre, v. 11, n. 19/20, p.139-165, jan./dez. 2004 
verdades historicamente construídas - oscilam entre a filosofia da história (Hegel) e uma ontologia fundante da historização (Heidegger) e encaminham-se para uma mesma lógica, que é a típica do campo filosófico: a des-historicização.

Para além das diferenças, têm em comum o fato de aniquilarem a História enquanto tal, fazendo coincidir o alfa e o ômega, a arche e o telos, o pensamento passado com o pensamento presente que o pensa melhor que ele se pensou - segundo a fórmula de Kant que todo o historiador da filosofia reinventa espontaneamente a partir do momento em que entende dar sentido ao seu empreendimento (Bourdieu, 1998, p. 37).

É na explicitação das bases sociológicas da ontologia de Heidegger que as pretensões imperialistas da Sociologia de Bourdieu ficam mais explícitas. Heidegger estaria anexando a História à Filosofia ao propor uma ontologia cuja ambição denegada é dar um fundamento a si própria que "é inseparável da recusa de tomar conhecimento da gênese empírica dessa ambição" (Bourdieu, 1998, p. 40). Contra a hermenêutica ontológica, em sua pretensão de encontrar a força da lucidez numa reapropriação autêntica do sentido originário do passado que sobrepujaria os limites inerentes às preconcepções do historiador, Bourdieu toma o partido do historiador e pretende uma história do campo escolástico como única fonte possível de lucidez (científica).

Se as ciências humanas procedem necessariamente a uma historicização de todo o espaço da representação, a Filosofia só pode erguer contra elas uma "historicidade da verdade que as ciências não dominam" e que se dá ou pela hermenêutica filosófica, ou por uma filosofia da história que está além do labor historicizante fundado na empiria. Investindo contra essas duas possibilidades de des-historicização, Bourdieu enquadra o movimento de Foucault, de Derrida e do conjunto da vanguarda da Filosofia francesa dos

Anos 90, Porto Alegre, v. 11, n. 19/20, p.139-165, jan./dez. 2004 
anos 60 no mesmo quadro das lutas da ontologia hermenêutica de Heidegger contra a historicização radical. Os pensamentos filosóficos francês e alemão são vistos pelo sociólogo como "luta contra as ciências sociais do seu tempo, nomeadamente a que consiste em virar contra as ciências as suas próprias aquisições" (Bourdieu, 1998, p. 24).

A proposta sociológica é desfazer as pretensões de lucidez filosófica, colocando, no lugar do golpe do "sentido originário" que fundaria filosoficamente a historicidade, a análise históricosociológica da lógica específica do campo escolástico e das disposições e crenças socialmente reconhecidas num momento dado do tempo como "filosóficas" ou "científicas". Essa seria a única possibilidade que uma análise dos processos de produção do conhecimento teria de escapar parcialmente das contingências históricas que pesam sobre ela mesma. "Referir a história dos conceitos ou dos sistemas filosóficos à história social do campo filosófico parece negar na sua própria essência um ato de pensamento tido por irredutível às circunstâncias contingentes e anedóticas do seu aparecimento" (Bourdieu, 1998, p. 37).

Diferente da Filosofia, que se propõe a se purificar das contingências da História, a Sociologia da Sociologia seria capaz de voltar as armas da História contra si mesma no movimento de objetivação da relação do sociólogo com relação a seu objeto de estudo e na objetivação da tentação do sociólogo de objetivar seus concorrentes, fazendo uso da ciência das estratégias para colocar essa estratégia especial - o poder da objetivação - a seu favor de modo privilegiado (Bourdieu, 1998, p. 54). Cada campo escolástico institui um conjunto de pontos de vista com pretensões à universalidade e que são necessariamente concorrentes entre si.

A sublimação das pretensões imperialistas de cada campo realiza-se de forma mais acabada na Sociologia porque só ela explicita como "os agentes, na sua luta para imporem o veredicto imparcial, quer dizer, para fazerem reconhecer a sua visão como objetiva, dispõem de forças que dependem da sua pertença a campos objetivamente hierarquizados e da sua posição nos campos respectivos" (Bourdieu, 1989, p. 55). O privilégio epistemológico da Sociologia 
residiria no fato de que só ela proporcionaria as condições de utilização das ferramentas analíticas de seu tempo contra as pretensões de acesso privilegiado ao real que emanam de seu próprio espaço. Ao aplicar ao próprio sociólogo essa exegese sociológica, a Sociologia crítica o destitui da posição do censor que traça as fronteiras doreal. A conseqüência desse desdobramento epistemológico é o desengajamento da Sociologia de qualquer militância a favor da definição ou redefinição das fronteiras do mundo social ou de previsões proféticas que podem se transformar em prescrições mais ou menos autorizadas pelos usos emblemáticos dos recursos retóricos da cientificidade.

\section{A arqueologia das ciências humanas como evacuação}

O empreendimento de Foucault pode ser visto como o inverso estrutural daquele de Bourdieu numa mesma matriz epistêmica. Trata-se, ainda aqui, de desmantelar as pretensões da fundamentação última que legitimaria ideologicamente a versão do enunciador atual. Tal desmantelamento faz-se articulando a história do saber à história das relações de poder, historicização essa que não deixa de ser um empreendimento filosófico. É contra as ciências humanas que essa historicização processa-se e, portanto só pode se apresentar como ontologia histórica. Em lugar da posição assumida por Bourdieu, de usar as ciências humanas para anexar territórios analíticos à Filosofia, trata-se, em Foucault, de erigir a Filosofia contra as ciências humanas num modo de operar tão historicizante quanto o dessas mesmas ciências.

A injunção bachelardiana a que se transforme o fazer filosófico em trabalho com dimensão empírica sob o modelo sombrio dos pequenos acúmulos permanentes típico dos cientistas está também presente em Foucault, mas de um modo diferente daquele operado na obra de Bourdieu. Bourdieu retira de Bachelard a possibilidade de demarcar a fenomenologia científica daquela do senso comum, enquanto Foucault usa o modo de demonstração bachelardiano das raízes fantásticas das ciências para desmantelar as pretensões das

Anos 90, Porto Alegre, v. 11, n. 19/20, p.139-165, jan./dez. 2004 
ciências humanas. Nem teoria nem proposta de uma nova metodologia para se fazerem as ciências do mundo social; trata-se de, para o Foucault da arqueologia, situar, nas grandes conformações discursivas, cujas unidades parecem-nos naturalizadas, as perturbações de continuidade, as rupturas, as descontinuidades que tornariam insustentável o brilho "original" das ciências atuais. Desordenar o senso estabelecido sobre a importância dos discursos constitui a primeira investidura de Foucault para desestabilizar as ciências humanas e suas pretensões de autofundamentação numa longa história do espírito humano.

A noção de descontinuidade toma um lugar importante de instrumento e objeto de pesquisa impondo recortes inéditos cujo fio condutor só pode ser dado pelas injunções das problemáticas presentes. Não se trata, portanto, de um empreendimento historiográfico de busca das origens, da procura dos antecedentes e de reconstituição de tradições. A história reaparece nessa discussão filosófica como jogo de correlações, quadro de relações, séries de séries, espaço de uma dispersão de forças sociais.

O efeito de superfície dessa crítica do documento é a desorganização de todo o nosso espaço categorial, de modo a fazer surgirem novas indagações, questões inusitadas, problemáticas até então não-formuláveis e que desestabilizam nossas certezas atuais. Esse efeito é o que conduz, na verdade, as apostas em termos de recorte de períodos e estabelecimento de corpus discursivos.

Essa chamada ao trabalho minucioso de organização, seriação, seleção e identificação das grandes questões filosóficas no interior de uma documentação vasta, local e relegada como impertinente impõe uma nova modalidade de erudição: o conhecimento exaustivo de um colecionador de textos menores de uma época anterior e cujos efeitos são mais contundentes na atualidade do que os grandes textos já demasiadamente discutidos e, portanto, de algum modo neutralizados em seus efeitos práticos.

Essa é uma das vertentes das mais conseqüentes da história das ciências, cujo modelo é encontrado em Bachelard e transplantado para a analítica do social. Trata-se de desconstituir as formulações

Anos 90, Porto Alegre, v. 11, n. 19/20, p.139-165x, jan./dez. 2004 
estabelecidas, por meio da exposição do começo abrupto de um novo modo de enunciar - a ruptura - em que de forma vacilante e incerta ainda se explicitam as normatizações mais arbitrárias que depois serão matizadas, naturalizados e revestidas de capas humanísticas.

A conseqüência mais explosiva desse tipo de empreendimento teórico é a dissolução da longa fiação do progresso da consciência ou ideologia da razão, isso que gerou a mais intensa controvérsia teórica da segunda metade do século XX francês sob o título de morte do sujeito. Contra a teleologia que busca dar sentido à inércia do passado numa totalidade cujo sentido deriva das injunções presentes, Foucault nos propõe uma problematização do presente através da desorganização dos corpora textuais do passado. Esse tipo de empreendimento histórico-filosófico desabriga a soberania da consciência dissolvendo a função fundadora de sujeito e a ilusão da restituição do passado numa totalização que seria a tomada de consciência do si do humano na história.

Essa descentralização do sujeito e da história, que pode ser visto como caudatário de uma história marxista de teor descontinuísta, da genealogia de Nietzsche, da psicanálise, da etnologia e da lingüística estruturalista, propõe-se a desmantelar o uso ideológico da história totalmente referida à atividade sintética do sujeito, a desfazer as últimas sujeições antropológicas presentes ainda nas ciências do homem, para fazer ver o ser que se dá errante e descontínuo.

É a partir dessa operação sistemática de relativização do humanismo ocidental que Foucault se coloca a questão das condições de possibilidades das ciências humanas. As ciências humanas emergiram quando deslocamentos epistemológicos tornaram possível tomar como objeto o fato de sujeitos terem representações. Isso nada mais é do que um acontecimento discursivo. Não se trata da tomada de consciência de um objeto sempre já aí, nem de um refinamento e mais precisão na abordagem de fatos sobre os quais sempre já se discursara. Trata-se da emergência de algo novo, datado e com um prazo de validade. É quando a Biologia libera o conceito

Anos 90, Porto Alegre, v. 11, n. 19/20, p.139-165x, jan./dez. 2004 
de estrutura, a Economia torna tratáveis, no plano da consciência, os conflitos dotados de leis próprias resultantes da complexificação da produção e das trocas e quando a Lingüística indica a persistência dos sistemas significantes sob nossas representações, que uma descontinuidade discursiva instaura-se para fazer emergir o homem como o plano em que a estrutura, o conflito e o sistema duplicamse na representação que se pode fazer dos fenômenos biológicos, econômicos e lingüísticos.

Lá onde se liberam representações, verdadeiras ou falsas, claras ou obscuras, perfeitamente conscientes ou embrenhadas na profundidade de alguma sonolência, observáveis direta ou indiretamente, oferecidas naquilo que o próprio homem enuncia ou detectáveis somente do exterior (Foucault, 1995, p. 369).

As ciências humanas emergem como dobras da Biologia, da Economia, da Filologia - uma das teses polêmicas de As palavras e as coisas sobre a qual não se tiraram ainda conseqüências para os esforços atuais de interdisciplinaridade -, etnociências específicas dessa região epistêmica que é o humanismo ocidental. Nesse sentido, a Psicologia seria uma biologia etnizada pelo humanismo dessa fase cultural ocidental, assim como a Sociologia seria um desdobramento regional da Economia, e a Antropologia com relação à Filologia.

A injunção de se historizarem radicalmente as possibilidades do conhecimento para se chagar ao a priori de onde emergem as ciências do homem não deve aqui correr o risco da antropologização dos demais espaços da episteme moderna. Não se trata, em Foucault, de se fazer uma Sociologia das ciências, mas de se fazer uma ontologia das relações de forças entre formações discursivas. Nesse sentido, as ciências humanas aparecem como duplicação com pretensões transcendentais em relação às outras ciências, numa "espécie de mobilidade transcendental": 
Bourdieu e Foucault: derivas de um espaço epistêmico

Não cessam de exercer para consigo próprias uma retomada crítica. Vão do que é dado à representação ao que torna possível uma representação, mas que ainda é uma representação. De maneira que elas buscam menos, como as outras ciências generalizarse [...] do que desmistificar-se sem cessar: passar de uma evidência imediata e não-controlada a formas menos transparentes, porém mais fundamentais (Foucault, 1995, p. 381).

É por se situar entre a analítica da finitude e a Biologia, a Economia e a Lingüística que as ciências humanas têm um estatuto epistêmico problemático. Efetivamente tratam como objeto o que é sua condição de possibilidade, vão do que é dado à representação para o que toma possível a representação, são ciências que se fazem num movimento que vai de uma evidência não-controlada às formas mais fundamentais que garantem a emergência de representações. Trazem subjacente o projeto de reconduzir a consciência às suas próprias condições reais de possibilidade. É contra esse jogo, que é ainda o de Bourdieu, que a arqueologia se investe: uma ontologia no lugar de uma sociologia das representações que precisaria depois fazer uma sociologia de si mesma.

Desse prisma, compreendem-se de um modo novo alguns fenômenos insólitos das ciências humanas contemporâneas. O lugar simultaneamente marginal e central nas ciências humanas das etnociências deve-se ao fato de que todas elas são basicamente etnociências. Sendo as ciências humanas não mais do que reduplicação da Economia, da Biologia e da Lingüística, a Etnobiologia, por exemplo, seria objeto privilegiado de uma análise que nunca deixaria de também ser ela mesma uma etnociência. Mas, diz-nos Foucault, a etnociência é efetivamente apenas isso, uma hipoepistemologia, percurso marginal no empreendimento epistêmico atual. Da mesma forma, a Antropologia Econômica nunca se firmou como ramo interessante da Economia e nem mesmo se consolidou como disciplina interior à Etnologia.

Anos 90, Porto Alegre, v. 11, n. 19/20, p.139-165, jan./dez. 2004 
A recusa de Foucault em reconhecer estatuto de ciências para as ciências humanas não se deve à falta de rigor científico, pelo menos no sentido de ausência do tipo de formalização de que a matematização poderia ser um índice, mas pelo efeito de transferência de modelos externos, precisamente pelo efeito antropologizante dessa transferência do plano sistêmico para um plano de representação que tem o homem como centro.

A oposição entre estrutura e ação ou entre explicação e compreensão (objetivismo versus subjetivismo) aparece deslocada, nessa análise foucaultiana, na exposição dos jogos de oposições e combinações de modelos conceituais retirados da Biologia, Economia e Lingüística. Enquanto predominou, nas ciências humanas, o triedo conceitual função, conflito e significação, essas ciências tenderam a uma arriscada e insustentável antropologização dos saberes. Quando predominaram os conceitos mais sistêmicos (objetivistas) de sistema, regras e normas, as ciências humanas passaram a enfrentar a representação no que ela carrega de dimensão inconsciente, informulável: o impensado, o sistematismo que torna a representação possível e que não se deixa pensar a si mesma, a menos que se abandone o ponto de vista do humano como lugar de emergência do sujeito da análise.

Sobretudo no momento de As palavras e as coisas, Foucault parece querer se ver situado no interior desse grande movimento geral de desantropologização dos saberes de que a Psicanálise e a Etnologia estruturalistas são expressões proeminentes. Porém, uma ambição de fundo demarca Foucault do estruturalismo das ciências humanas: um outro projeto não apenas alternativo às ciências humanas, mas que pode tomá-las como objeto; um projeto que não aquele que faz a dimensão inconsciente recuar à medida em que a consciência é interpelada em suas condições de possibilidade. Tratase de enfrentar diretamente a dimensão impensada das próprias ciências humanas.

Se nos lembrarmos que, na arqueologia, Foucault propõe outras modalidades de caráter não necessariamente epistêmicos de problematização do presente, podemos tomar esse esforço

Anos 90, Porto Alegre, v. 11, n. 19/20, p.139-165, jan./dez. 2004 
arqueológico de As palavras e as coisas como uma posição discursiva deslocada em relação às ciências do homem e simultaneamente em relação a quaisquer padrões de cientificidade. Trata-se aqui de uma problematização radical da atualidade num discurso sem estatuto, destituído de autoridade epistêmica, definitivamente a-científico.

Sem entender essa possibilidade de uma critica não-epistêmica, Habermas (1990) terá a pretensão de desmantelar a arqueologia e genealogia, na medida em que Foucault ver-se-ia impossibilitado de alicerçar cientificamente sua demonstração da relação problemática entre ciências humanas e as formas locais de relações de poder. Segundo Habermas, esse empreendimento correria sempre o risco de ver seu arsenal relativizador destituindo o próprio lugar de emergência do discurso foucaultiano. Essa é uma questão que se pode colocar a quem tem a pretensão de cientificidade. Para aquele que se situa no operar de uma política do presente, a questão da fundamentação da própria possibilidade de enunciação não se coloca. A guerra contra as técnicas de identificação, que institucionalizam sujeitos a partir dos esquadrinhamentos investigativos típicos das ciências humanas, dá-se pela recusa a autolocalização.

Existe em muita gente, penso eu, um desejo semelhante de não ter de começar, um desejo de se encontrar, logo de entrada, do outro lado do discurso, sem ter de considerar do exterior o que ele poderia ter de singular, de terrível, talvez de maléfico. A essa aspiração tão comum, a instituição responde de modo irônico; pois que toma os começos solenes, cerca-os de um círculo de atenção e de silêncio, e lhes impõe formas ritualizadas, como para sinalizá-los à distância (Foucault, 1970, p. 6).

Essa recusa significaria um ponto cego e uma desvantagem com relação à tradição hermenêutica ou à localização histórica de uma sociologia crítica tal como faz Bourdieu? De fato, Foucault não deixa de tomar como tema de reflexão, para se auto-situar - com

Anos 90, Porto Alegre, v. 11, n. 19/20, p.139-165, jan./dez. 2004 
quase a mesma intensidade empírica que aparece em Bourdieu -, o momento histórico de emergência da história das ciências de que ele mesmo se faz caudatário. Mas trata-se aqui de uma política de problematização do presente.

Na modificação do prefácio dedicado à obra de Canguilhem O normal e o patológico, Foucault retoma a história da História das Ciências, pelo momento em que Husserl é introduzido na França. Aprofunda-se na França, com a instalação dessa referência filosófica, a questão da historicidade do conhecimento, e o debate desdobrase em duas possibilidades de se negar o empreendimento de busca de uma fundamentação primeira:

Pronunciadas em 1929, modificadas, traduzidas e publicadas pouco depois, as Meditações cartesianas foram precocemente o que esteve em jogo em duas leituras possíveis: uma que, na direção de uma filosofia do sujeito, procurava radicalizar Husserl e não devia tardar a reencontrar as questões de Sein und Zeit; tratase do artigo sobre a "Transcendance de l'ego", em 1935; a outra que vai remontar aos problemas fundadores do pensamento de Husserl, os do formalismo e do intuicionismo (Foucault, 2000, p. 354).

De um lado, coloca-se a questão da inserção da existência no mundo da vida e a possibilidade da abertura de uma pesquisa sobre a historicidade fundamental do ser, programa de investigação que encontra na França expressões maiores em Sartre e Merleau-Ponty. De outro lado, situa-se a inserção das ciências numa história da razão cujas contingências, por serem prosaicas, demandam apenas a metodologia do historiador para uma matéria subtraída às formas instituídas de filosofar.

Trata-se, nessa segunda linhagem, a de Bachelard e Canguilhem, de fazer funcionar a Filosofia e os temas do Aufklärung em "domínios bem precisos" da história das ciências. Mas a amplitude desse novo modelo de filosofar não se restringe a essa delimitação

Anos 90, Porto Alegre, v. 11, n. 19/20, p.139-165, jan./dez. 2004 
no estudo histórico das ciências: é possível, mais ainda, perguntar aos processos de racionalização pelas suas ligações a formas de dominação e hegemonia política. É essa a extensão que Foucault particularmente dá à história das ciências praticadas por Canguilhem e Bachelard.

Mas qual é a filosofia dessa história das ciências? Aqui a proposta de Foucault faz-se diferente da de Bourdieu: não se trata de uma história à maneira da história geral. No modo como Foucault lê o empreendimento de Canguilhem, faz-se ressaltar uma perspectiva ontológica específica: a da história epistemológica específica da Biologia. Evitando o reducionismo sociológico, cada ciência levantaria seus problemas específicos para o historiador a partir de uma ontologia própria. Para o historiador das ciências tal como visto por Foucault, o que está em jogo é a questão da relação entre o ponto de vista do historiador e o ponto de vista do cientista. A ontologia perspectivista é o modo como o perspectivismo do historiador dissolve-se na ontologia da ciência historizada. E a ontologia própria ao momento atual da Biologia emerge do modo como o ser do homem enraíza-se na vida: "do logos do código e da decodificação", emerge a possibilidade do erro como especificidade da vida, e a conceitualização do mundo, típica do humano, aparece apenas como uma duplicação das possibilidades do erro próprias da vida:

O fato de o homem viver em um meio conceitualmente arquitetado não prova que ele se desviou da vida por qualquer esquecimento ou que um drama histórico o separou dela; mas somente que ele vive de uma certa maneira, que ele tem, com seu meio, uma tal relação que ele não tem sobre ele um ponto de vista fixo (Foucault, 2000, p. 363).

A fenomenologia hermenêutica, como uma das fontes do construtivismo mais intenso das ciências humanas na atualidade, instaurou o mundo vivido como "o sentido originário de qualquer ato de conhecimento”. Em contraposição, a ontologia do biólogo

Anos 90, Porto Alegre, v. 11, n. 19/20, p.139-165, jan./dez. 2004 
encontra as condições de possibilidade do conhecimento do lado do vivente. Trata-se do sistema vivo em lugar da consciência - reemerge aqui uma das polêmicas mais caras à trajetória do filósofo herdeiro do historiador das ciências: o anti-humanismo que contrapõe sistema à consciência, ao vivido, ao sentido originário. No limite, a vida - daí seu caráter radical - é o que é capaz de erro, por isso, é preciso "interrogá-la sobre esse erro singular, mas hereditário, que faz com que a vida desemboque com o homem, em um vivente que nunca se encontra completamente adaptado, em um vivente condenado a 'errar' e a se 'enganar'." (Foucault, 2000, p. 364).

Inserido o saber no errar daquele ser que nunca se adapta plenamente, libera-se a questão do poder como modalidade artificial de adaptação sempre presente nas relações sociais. Filosofar tornase o ato de perseguir o erro, de interrogá-lo quando esse erro ganha a forma das relações de poder, interpelação essa que se dá numa definitiva incapacidade de se fundamentar a si mesma, pura busca fadada ao fracasso do se adaptar do ser errante. A oposição do verdadeiro e do falso, os efeitos de poder e as instituições que se associam a essa partilha inserem-se assim no âmago da vida como a possibilidade de perturbação no sistema informativo do vivente. A vida apresenta-se, então, como código sujeito a perturbações. $\mathrm{O}$ que cabe aqui perguntar a partir dessa inserção da história das ciências nessa ontologia do vivente é, em primeiro lugar, sobre seus efeitos epistêmicos: se for sobre o erro ontológico de ser vivente que se instala a partilha verdade/erro, essa ontologia instala-se sobre as pretensões de verdade para perguntar pelas dimensões de poder associado a perturbações duplicadas nos códigos típicos dos viventes. Quais são as condições de possibilidades de retificação dos erros? Em segundo lugar se a ontologia que deriva da história das ciências biológicas é uma das ontologias possíveis, outras ontologias derivariam da história de outros campos epistêmicos. Uma ontologia perspectivista e pluralista emanaria desse procedimento de historicização das ciências, caso Foucault tivesse tido tempo para a retomada das questões deixadas pendentes na arqueologia? Se for 
certo que, com a genealogia, Foucault vai preferir se dedicar às formações discursivas menos epistemologizadas do que aquelas de ciências como a Biologia - a que Canguilhem se dedicara - para perceber nelas as modalidades de relação saber-poder, também se poderia perguntar em que medida desdobramentos em termos de estudos sociais das ciências como os de Latour não retomam um programa deixado em aberto na arqueologia.

\section{Da ruptura epistemológica ao erro}

Para resumir a discussão anterior, diria que, nessa história das ciências de matriz bachelardiana, Foucault opera um deslocamento conceitual de tal modo que, no lugar da descontinuidade, enfatizada na arqueologia, aparece o erro em seu último texto publicado em vida. O peso desse deslocamento numa contraposição com Bourdieu (particularmente o das Meditações Pascalinas) é o último tópico a ser explorado neste artigo.

A genealogia poderia, à luz desse último texto, ser lida como a analítica das imensas possibilidades do erro. Essa analítica foi uma obra construída contra a teleologia da razão. Para se tomar um exemplo de vulto similar, como essa historicização da razão pelo seu inverso - o erro - demarca-se da historicização da racionalidade no pensamento da escola de Frankfurt?

Não se buscam, na obra de Foucault, os efeitos perversos dos grandes processos de racionalização. Trata-se de decompor a noção de racionalização em processos específicos e localizados, de analisar processos restritos de hierarquização, modalidades pouco articuladas de padronização, instâncias precárias de adaptação dos grandes imperativos de racionalização e que sofrem as resistências das forças locais, a lenta erosão das injunções dominantes. São esses processos errantes de adaptação dos múltiplos esforços de racionalização dominantes que podem ser submetidos a análises minuciosas sob conceitos como os de dispositivos, governabilidade, biopoder, saber-poder. 
Ao retomar, de Canguilhem, a noção de erro, Foucault esboça seu último gesto explícito de deslocamento em relação Heidegger. Do ser disciplinado pelo modelo do aprisionamento moderno ressaltado em Vigiar e Punir ao caráter errante da confissão sexual, trata-se da ontologia do erro, de "um vivente que nunca se encontra completamente adaptado, em um vivente condenado a errar e a se enganar" (Foucault, 2000, p. 364).

A noção de erro não permite aqui uma unificação totalizante da experiência humana. O que essa noção permite abrir é a idéia da multiplicidade incorrigível das experimentações. Não se trata de encontrar, nessa espécie de nomadismo do ser errante, uma espécie de essência do homem. Até ao último texto, Foucault permanece anti-humanista nesse sentido da recusa de qualquer essência transhistórica para o homem. O erro é jogado contra qualquer possibilidade de se pensar um sujeito transcendental: "Será que toda a teoria do sujeito não deve ser reformulada, já que o conhecimento, mais do que se abrir à verdade do mundo, se enraíza nos erros da vida?".

Em seu derradeiro texto publicado em vida, contra a última grande filosofia do sujeito - a fenomenologia -, Foucault jogou Canguilhem. O vivente de Canguilhem contra o "vivido" da fenomenologia. Códigos e mensagens não são exclusivamente da ordem do vivido, da consciência, portanto do tipicamente humano, são produtos sistemáticos da vida, assim como o erro.

Os problemas que se acreditava serem os mais fundamentais do homem enquanto ser pensante pertencem na verdade à especificidade do problema da vida. O conceito é apenas um dos modos pelo qual o vivente extrai de seu meio informações e pela qual inversamente, ele estrutura seu meio (Foucault, 2000, p. 364).

Em Bourdieu, o processo de objetivação do pesquisador está ao serviço da reconstrução das possibilidades dessa ciência que é a

Anos 90, Porto Alegre, v. 11, n. 19/20, p.139-165, jan./dez. 2004 
Sociologia. O inconsciente epistêmico inerente a um campo de saber não se abre como em Foucault para uma ontologia específica porque há, em Bourdieu, um realismo crítico não submetido à dúvida sociológica e que é a condição sociológica de possibilidade da sociologia.

Usar os instrumentos científicos de seu tempo para expor os vínculos entre a razão escolástica e os interesses específicos que se constituem nesse campo propõe, como real, os pressupostos ontológicos inerentes a tais instrumentos conceituais (ilusio, habitus, campos...). Todas as outras ontologias que poderiam derivar de outras disciplinas e articulações conceituais aparecem como "mundo lúdico da conjectura teórica e da experimentação mental" cujo grau de vínculo com o real só pode ser definitivamente estabelecido pela Sociologia. Sob essa posição epistêmica, tudo o que acontece no campo escolástico fica suspenso como efeito de um jogo tipicamente escolar, portanto desconectado do real pela neutralização das urgências dos fins práticos típico do ser escolástico.

Poder-se-ia perguntar se essa crítica da razão escolástica, sendo produto das concorrências próprias do campo acadêmico, não carrega os limites desse tipo de dinâmica social que é a concorrência. Ao submeter a razão escolástica a uma crítica inevitavelmente escolástica, Bourdieu não se encontra aqui ameaçado por uma espécie de esquizofrenia na medida em que está condenado a dizer a historicidade e a relatividade das ciências e da Filosofia num discurso aspirando à universalidade e à objetividade, mas também preso às contingências de sua própria situação histórica? É problemático exigir simultaneamente que o sociólogo volte contra sua própria sociologia as armas relativizantes da história e que suspenda a si próprio de qualquer adesão ingênua às posições em jogo fora do campo científico, que abdique de tomar posições além dos limites impostos pelo campo e perceber que esse conjunto de injunções emana de um estado historicamente particular do campo científico. Isso significa uma injunção normativa a não retirar conseqüências da história relativa do campo científico, portanto tolher a multiplicidade potencial de discussões que se abrem na esteira do questionamento

Anos 90, Porto Alegre, v. 11, n. 19/20, p.139-165, jan./dez. 2004 
do processo de autonomização dessas razões locais que são as disciplinas acadêmicas. Por que obedecê-la? O arbitrário como vontade de potência clama para a possibilidade de ser restabelecido, sobretudo nos pontos sufocados pela regularidade dos discursos que se tornaram dominantes em nome da cientificidade. E é nesses pontos de abertura para críticas não-epistêmicas que se pode localizar as possibilidades de se estender o pensamento de Foucault.

\section{Conclusão}

Desde que naufragou a pretensão ocidental de constituição de uma "filosofia primeira" que iluminaria os caminhos da ciência, resta como base ainda de justificação da racionalidade do empreendimento científico a reconstrução racional daquilo que, após ocorrido, pode ser considerado conteúdo racional de um campo específico de pesquisa. O que Bachelard fundou foi uma modalidade de reconstrução racional associada a um historicismo que se contrapõe ao positivismo na medida em que enfatiza o caráter criativo e inventivo da fenomenotécnica científica. Desse modo, Bachelard cinde o fenômeno para as ciências e aquele que se dá enquanto senso comum, posição que seria apenas positivista se esse filósofo e historiador das ciências não tivesse de forma algo ambígua afirmado simultaneamente (l) o caráter quase-arbritrário (portanto, inventivo, histórico e relativo) do fazer cientifico e (2) as imensas exigências de rigor que a batalha sistemática contra o erro impõe.

Essa segunda dimensão da história das ciências bachelardianas é a que mais influencia Bourdieu. Da análise sociológica das condições de possibilidade do conhecimento científico que deriva dessa historicização radical, podem-se extrair posições normativas como aquelas que Bourdieu associa à exigência de autonomia do campo e à injunção permanente à ruptura com a doxa do próprio campo e, sobretudo, com as injunções externas ao campo. O que Bourdieu extrai de Bachelard, em última instância, é a possibilidade de normalizar o fazer científico, transformando o cientista num engajado em causa própria: a autonomia de seu espaço de produção cultural.

Anos 90, Porto Alegre, v. 11, n. 19/20, p.139-165, jan./dez. 2004 
Já Foucault vincula-se ao primeiro tópico das conseqüências da historicização bachelardiana, aquela da demonstração do arbitrário da racionalidade científica, seu caráter de prática social inventiva. Nesse terreno árido da relativização dos saberes, nenhuma intenção prescritiva sustenta-se.

Se, como vimos, o que está em jogo em todo esse espaço epistêmico é a possibilidade de se utilizar a história para se impulsionar o pensamento a ir além de sua adequação preestabelecida, de suas condições atuais de possibilidade, dois caminhos estabelecem-se. O sociológico desvenda as condições de possibilidades oferecidas pela estrutura do campo científico na atual conjuntura de pesquisa e reclama por mais autonomia como condição de auto-superação. O que aqui se prescreve é o que a própria análise histórica em constante processo de retificação pode ajudar a transpor.

O caminho do filósofo usa a história para nivelar os saberes consagrados aos saberes menores, aos conhecimentos destituídos trata-se aqui do resgate da dignidade das formas de discursos que não se tornaram dominantes, que produziram outras cintilações e que foram ofuscadas pelo modo como o saber dominante articulouse a modalidades locais de relações de poder, estendendo-se em rede de formas sociais e convicções reificadas. O esclarecimento é aqui o efeito da ação localizada do filósofo-historiador, e isso não se assenta em condições especiais de possibilidade, mas numa postura política no interior do pensamento, uma postura francamente contrahegemônica de problematização do presente.

Para finalizar, devo argumentar que a posição epistemológica de Foucault parece ser mais adequada às condições que se tem na Modernidade periférica de exercício da crítica do presente. O desdobramento das posições epistemológicas de Bourdieu, no sentido de que a concorrência no interior do próprio campo científico, em situação de autonomia relativa, é o motor de uma quase-transcendência, só pode ser aceitável se puder, de alguma forma, enriquecer-se de outras modalidades insuspeitadas - nãoepistêmicas - de superação da "tradição que nos somos". E é nesse

Anos 90, Porto Alegre, v. 11, n. 19/20, p.139-165, jan./dez. 2004 
sentido que aponta Foucault para outros saberes como fontes de renovação da crítica e para a pluralidade das ontologias científicas.

Numa situação de Modernidade periférica, essa discussão epistemológica fica particularmente tensa se levarmos em conta a inexistência de condições de possibilidade da autonomia dos campos científicos. Não fica claro, na posição de Bourdieu, se países que não constituem as condições de uma autonomia relativa do campo de pesquisa científica oferecem ainda assim condições de possibilidade de um pensamento que pode fazer surgir o inusitado e a exposição do impensado, pensamento em confronto crítico com as estruturas estabelecidas, em lugar de estar adequado a tais estruturas.

Esta conclusão deveria encaminhar para reflexões que apontassem para a readequação dessa discussão epistemológica para um contexto histórico como o brasileiro, que se apresenta como lugar de importação de modelos de institucionalização de pesquisas, mas em que, simultaneamente, essas instituições não funcionam como espaços dotados de autonomia suficiente para engendrar as lógicas específicas de produção e consagração científicas. Sob o hibridismo das lógicas de engajamento e buscas de retribuição dos cientistas sociais à brasileira, a crítica far-se-ia exercer apenas até o limite imposto pelas "causas" que regem os usos sociais dos emblemas do fazer científico.

Bourdieu revela-se, para nossos objetivos, menos importante que as reflexões que podem se estender na esteira de Foucault porque este último não toma Bachelard em sua dimensão normativa, mas, sobretudo, na positividade de seu modelo de reconstrução do inventivo (arbitrário) da razão científica. Se a posição de Foucault é aqui particularmente interessante, o é na medida em que parte de uma conjuntura histórica particular e toma a razão crítica como uma possibilidade e uma experimentação das possibilidades de pensar que a época em questão oferece.

Tais possibilidades não são associadas a condições sociais especiais, mas são aberturas ético-políticas que se criam como efeitos das tecnologias de si, parte das técnicas mais gerais de poder de uma

Anos 90, Porto Alegre, v. 11, n. 19/20, p.139-165, jan./dez. 2004 
determinada época. A questão ética que a Modernidade instaura para o pensador atual é a da possibilidade de contraciências, daelevação do saber local, marginal, alternativo aos saberes qualificados. Trata-se de tomar saberes incompetentes, insuficientes e locais e elevá-los à dignidade de crítica às possibilidades fechadas pelas regularidades discursivas que se estabeleceram como hegemônicas e perceber neles outras ontologias num mundo em perspectivas.

Aqui a particular importância de Foucault reside no fato de possibilitar a recusa à chantagem de que o pensamento contrahegemônico só se dá nas condições da ruptura epistemológica assegurada pelo trabalho coletivo de concorrência no interior de um campo científico diferenciado em suas lógicas de consagração social. Em Foucault, o esclarecimento é sempre uma possibilidade - rara - no interior das condições específicas de um modo de operar o pensamento. Restariam a discutir as possibilidades de combinação das duas posições epistemológicas para se vislumbrarem os potenciais aprofundamentos do pensamento crítico na Modernidade periférica.

\section{Bourdieu and Foucault: derivation of an epistemic space}

Abstract. In this article the author discusses the bachelardian episthemological basis of Bourdieu's and Foucault's works, aiming at assessing their pertinence to a sociology of modernity in the periphery. Bachelard founded a modality of rational reconstruction associated to a historicization opposed to positivism, since it emphasizes the creative and inventive character of the scientific phenomenotechnology. Bourdieu takes from Bachelard the imposition of an epistemological rupture between the phenomenon reconstructed in science and the one presented to common sense. Foucault uses the bachelardian method of demonstration of the fantastic roots of science to unmask the pretensions of human sciences. It is suggested in this article that the extension of the foucaultian epistemological position is heuristically more productive, being still promising to places of enunciation that intend to unveil the way modernity presents itself in the periphery.

Keywords: Michel Foucault. Pierre Bourdieu. Gaston Bachelard. Modernity.

Anos 90, Porto Alegre, v. 11, n. 19/20, p.139-165, jan./dez. 2004 
José Carlos dos Anjos

\section{Nota}

${ }^{1} \mathrm{O}$ paradoxal em Bachelard é que o autor elogia a ciência pelas suas imensas exigências de rigor e desprezo visceral pelo senso comum, o que parece positivista, ao mesmo tempo em que toma como irrealista o pensamento científico em seu mais alto grau de abstração: “o pensamento científico é então levado para ‘construções' mais metafóricas que reais” (Bachelard, 1996, p.7).

Referências

BACHELARD, Gaston. A formação do espirito científico. Rio de Janeiro: Contraponto, 1996.

BOURDIEU, Pierre. A economia das trocas lingüisticas: o que falar quer dizer. São Paulo: Ed. da USP, 1996. . Meditações pascalinas. Oeiras: Celta, 1998.

Poder simbólico. Lisboa: Ediel, 1989.

FOUCAULT, Michel. A arqueologia do saber. Rio de Janeiro: Forense Universitária, 1987.

Arqueologia das ciências e história dos sistemas de pensamento. Rio de Janeiro: Forense Universitária, 2000

As palavras e as coisas. São Paulo: Martins Fontes, 1995.

A ordem do discurso: aula inaugural no College de France, pronunciada em 2 de dezembro de 1970. 5.ed. São Paulo: Loyola, 1999.

HABEMAS, Jürgen. O discurso filosófico da Modernidade. Lisboa: Dom Quixote, 1990. 